LAWRENCE LIVERMORE NAT IO N A L LABORATORY
Tomographic Imaging of Upper Mantle P-wave Velocity Heterogeneity Beneath the Arabian Peninsula

Yongchoel Park, Andrew Nyblade, Arthur Rodgers

September 1, 2004 
This document was prepared as an account of work sponsored by an agency of the United States Government. Neither the United States Government nor the University of California nor any of their employees, makes any warranty, express or implied, or assumes any legal liability or responsibility for the accuracy, completeness, or usefulness of any information, apparatus, product, or process disclosed, or represents that its use would not infringe privately owned rights. Reference herein to any specific commercial product, process, or service by trade name, trademark, manufacturer, or otherwise, does not necessarily constitute or imply its endorsement, recommendation, or favoring by the United States Government or the University of California. The views and opinions of authors expressed herein do not necessarily state or reflect those of the United States Government or the University of California, and shall not be used for advertising or product endorsement purposes.

This work was performed under the auspices of the U.S. Department of Energy by University of California, Lawrence Livermore National Laboratory under Contract W-7405-Eng-48. 


\title{
Tomographic Imaging of Upper Mantle P-wave Velocity Heterogeneity Beneath the Arabian Peninsula
}

\author{
Yongchoel Park, Andrew Nyblade \\ Geosciences Department, Pennsylvania State University \\ Arthur Rodgers \\ Earth Sciences Division, Lawrence Livermore National Laboratory
}

Technical Report

August 31, 2004

We report preliminary estimates of three-dimensional P-wave velocity structure beneath the Arabian Peninsula estimated from travel time delay tomography. We have completed travel time measurement and inversion of a partial data set provided by King Abdulaziz City for Science and Technology (KACST). This study builds on previous work by Benoit et al. (2003) following the methods of Van der Carr and Crosson (1990) and Van der Carr (1990). Data were collected from the Saudi Arabian National Digital Seismic Network (SANDSN) operated by KACST. The network consists of 38 stations (27 broadband and 11 short-period). We augmented the KACST data with delay times measured from permanent Incorporated Research Institutions for Seismology (IRIS) stations in the region (RAYN, EIL and MRNI). Travel time delay data from Benoit et al. (2003) was not included in the inversions discussed below, but will be included in future analysis.

For the KACST data, we used 131 earthquakes with P-wave arrivals in the distance range $30^{\circ}-90^{\circ}$, resulting in 1716 ray paths. The data from Benoit et al., (2003) included 178 earthquakes and 792 rays. Figure 1 shows the earthquake distributions for the two data sets. Natural seismicity observed in Arabia in this distance range results in many events from the northeastern azimuths and very few events from southern and western azimuths. 
The inversion procedure consists of four steps. First, the P-wave travel time delays were measured from large teleseismic earthquakes using the Multi-Channel Cross-Correlation method of (Van der Carr and Crosson, 1990). Second, the ray paths and travel time residuals are computed. Residuals are formed by subtracting the theoretical travel time predicted from the global average one-dimensional velocity model iasp91 (Kennett and Engdahl, 1991) from the observed travel time. Third, the partial derivatives of the ray paths are computed for the gridded upper mantle model. Then the travel time residuals are inverted for upper mantle velocity structure. The method uses an iterative non-linear ray tracing algorithm to allow for ray bending by three-dimensional structure. Figure 2 shows the grid of points on which the velocity model is computed during the inversion.

So far we have only inverted delay times measured from the KACST and IRIS data sets alone. The resulting tomographic images of upper mantle velocity structure are shown in Figures 3-6. These figures show the velocity perturbations relative to the iasp91 model (Kennett and Engdahl, 1991). The models reveal lateral variations in P-wave velocity of $\pm 1 \%$. The most striking features of these images are the strong low velocities beneath the southern Arabian Shield (Asir Province) and Red Sea and the eastern edge of the Arabian Shield. We infer low velocities beneath the Dead Sea Transform and Gulf of Aqaba at depths below $200 \mathrm{~km}$. A broad region of low velocities is inferred beneath the northern Arabian Shield below $200 \mathrm{~km}$. Results from the combined KACST and IRIS data are broadly consistent with the results of Benoit et al. (2003) with the exception of velocities in the northern Arabian Shield. Benoit et al. (2003) inferred high velocities beneath the northern Arabian Shield and the KACST data results in lower than average velocities.

Preliminary interpretation of these features would suggest that low velocities beneath the Gulf of Aqaba and southern Arabian Shield and Red Sea are related to mantle upwelling and seafloor spreading. Low velocities beneath the northern Arabian Shield may be related to volcanic centers. The low velocity feature near the eastern edge of the Arabian Shield and western edge of Arabian Platform are mysterious, but could be related to mantle flow effects near the interface of lithospheres of different thickness. 
Future work will involve making more travel time delay measurements from the remaining KACST data sets. Particular emphasis will be placed on events from southwestern and northwestern azimuths. We will also add the travel time delay data from Benoit et al. (2003) and additional IRIS and other open stations as appropriate. Data from the 1995-7 Saudi Arabian PASSCAL Deployment used by Benoit et al. (2003) will improve the ray path coverage in the central Arabian Shield. However, baseline differences between the two data sets will have to be estimated and considered before inverting the combined data sets.

\section{Acknowledgements}

This work was performed under the auspices of the U.S. Department of Energy by University of California Lawrence Livermore National Laboratory under contract No. W405-Eng-48. This is LLNL contribution UCRL-TR-206337.

\section{References}

Benoit, M., A. Nyblade, J. vanDecar and H. Gurrola, Upper mantle P wave velocity structure and transition zone thickness beneath the Arabian shield, Geophys, Res. Lett., 20, 38, 2003.

Kennett, B. and E. R. Engdahl (1991). Travel times for global earthquake location and phase identification, Geophys. J. Int., 105, 429-465.

VanDecar, J. C., Upper mantle structure of the Cascadia subduction zone from non-linear teleseismic travel time inversion, Ph.D. thesis, Univ. of Wash., Seattle, 1991.

VanDecar, J. C., and R. S. Crossen, Determination of teleseismic relative phase arrival times using multi-channel cross-correlation and least-squares, Bull. Seismol. Soc. Am., 80, 150-169, 1990. 


\section{Figure Captions}

Figure 1. Earthquakes analyzed in this study. (a) Events for which we have measured KACST travel time delays. (b) Events used by Benoit et al. (2003). Lines indicate distances from central Saudi Arabia in $30^{\circ}$ increments.

Figure 2. The grid of points on which the velocity model is estimated. Stations of the SANDSN network are indicated by the white squares.

Figure 3. Map of lateral variations in P-wave velocities relative to iasp91 (Kennet and Engdahl, 1991) at $100 \mathrm{~km}$ depth. The contact of the Arabian Shield and Arabian Platform is indicated by the white line.

Figure 4. Same as Figure 3, but at $200 \mathrm{~km}$ depth.

Figure 5. Same as Figure 3, but at $300 \mathrm{~km}$ depth.

Figure 6. Same as Figure 3, but at $400 \mathrm{~km}$ depth.

Figure 7. Cross-section through the upper mantle along the Red Sea coast (profile A-A' shown in Figure 1). 

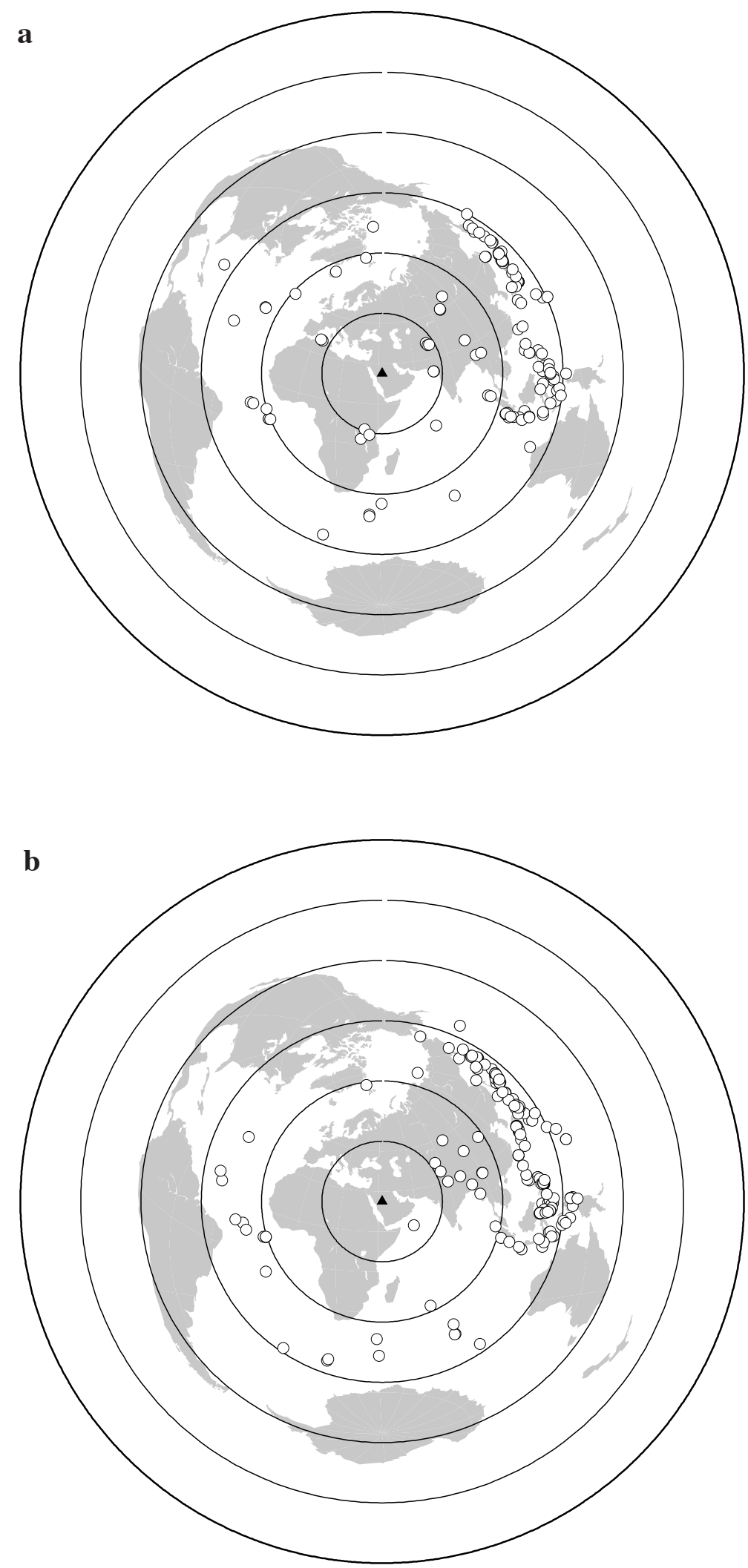

Figure 1. Earthquakes analyzed in this study. (a) Events for which we have measured KACST travel time delays. (b) Events used by Benoit et al. (2003). 


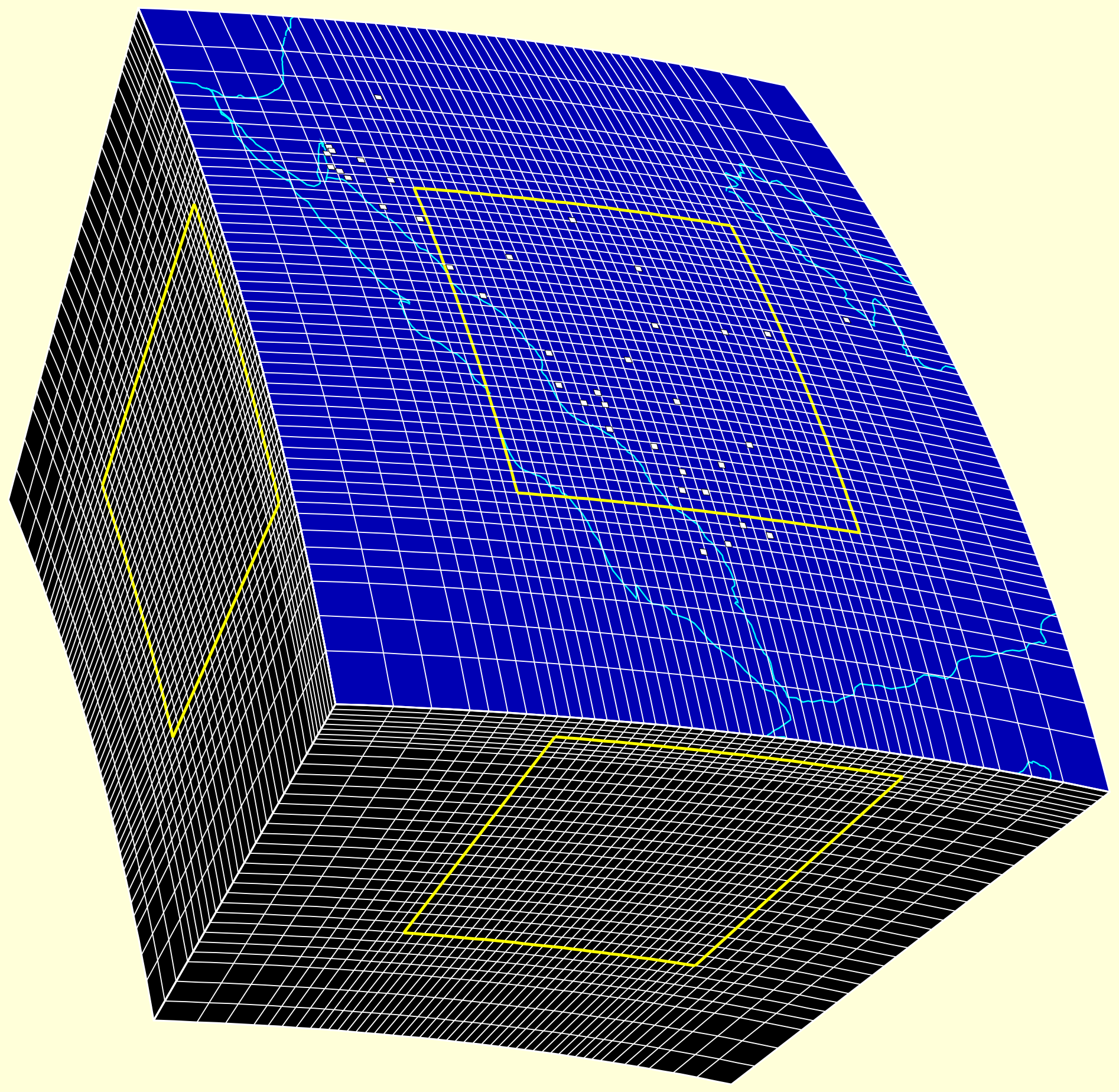

Number of knots in radius $=34$; latitude $=51$; longitude $=48$ Total number of knots $=83232$

Figure 2. The grid of points on which the velocity model is estimated. Stations of the SANDSN network are indicated by the white squares. 


\section{$100 \mathrm{~km}$}
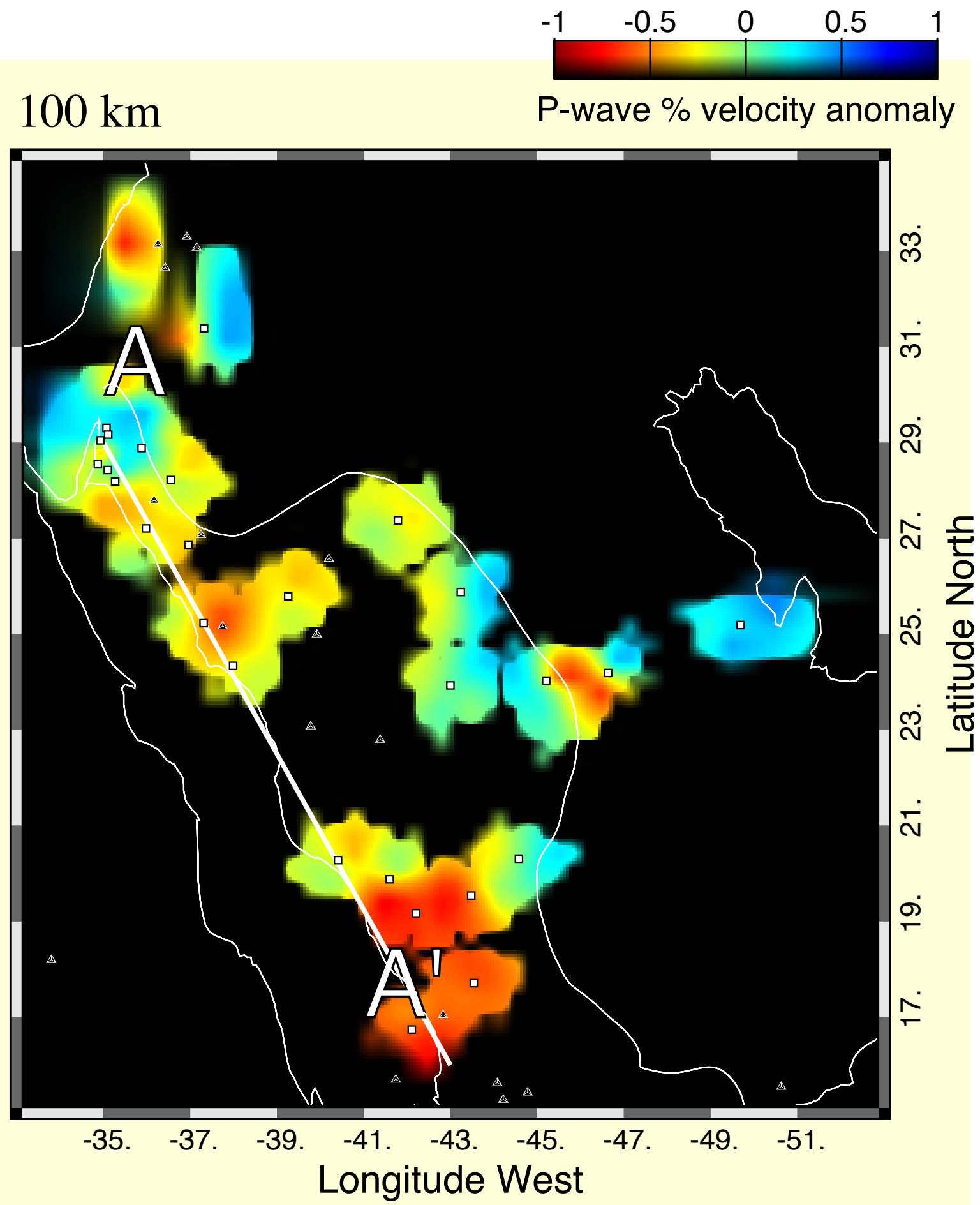

Figure 3. Map of lateral variations in P-wave velocities relative to iasp91 (Kennet and Engdahl, 1991) at $100 \mathrm{~km}$ depth. The contact of the Arabian Shield and Arabian Platform is indicated by the white line. 

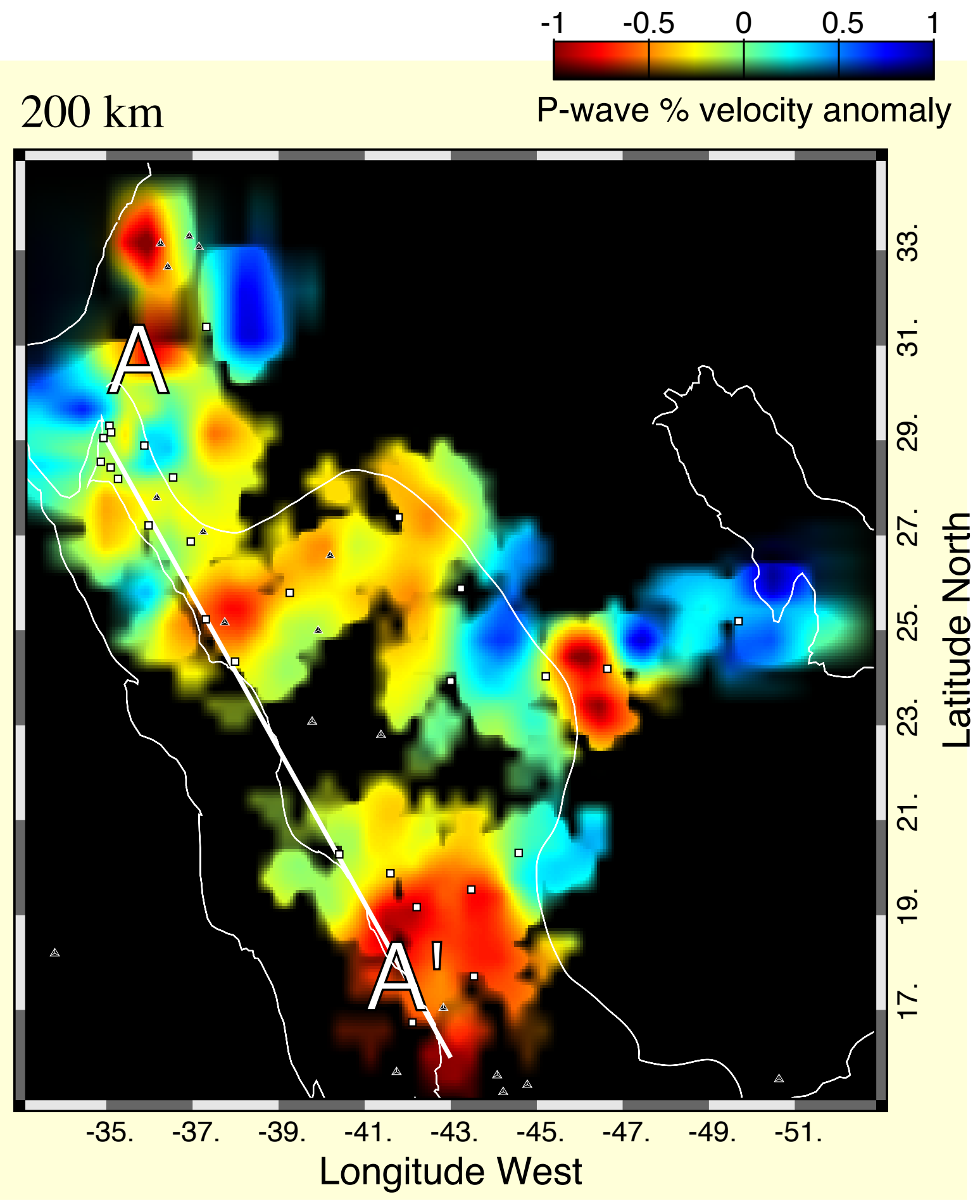

Figure 4. Same as Figure 3, but at $200 \mathrm{~km}$ depth. 

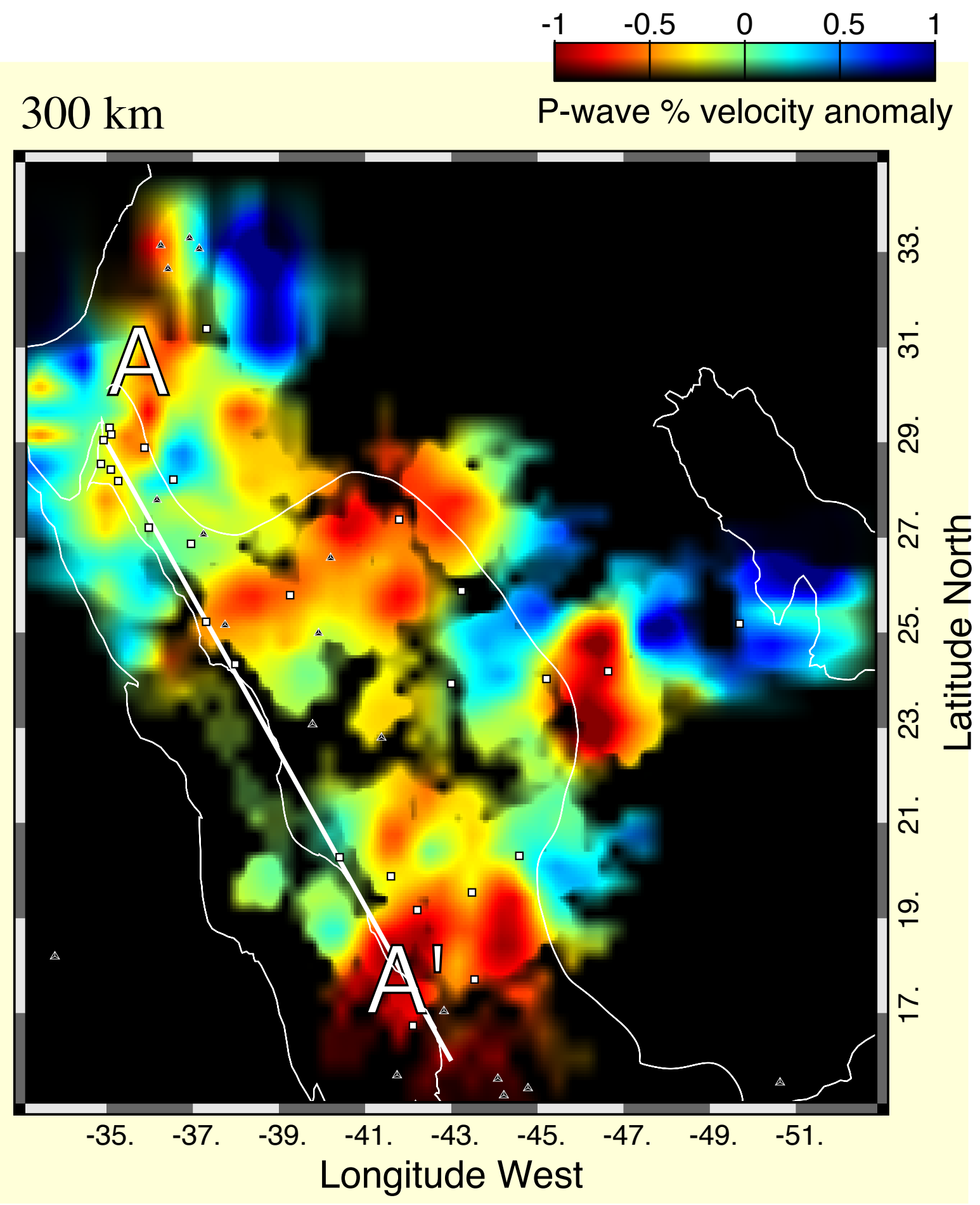

Figure 5. Same as Figure 3, but at $300 \mathrm{~km}$ depth. 

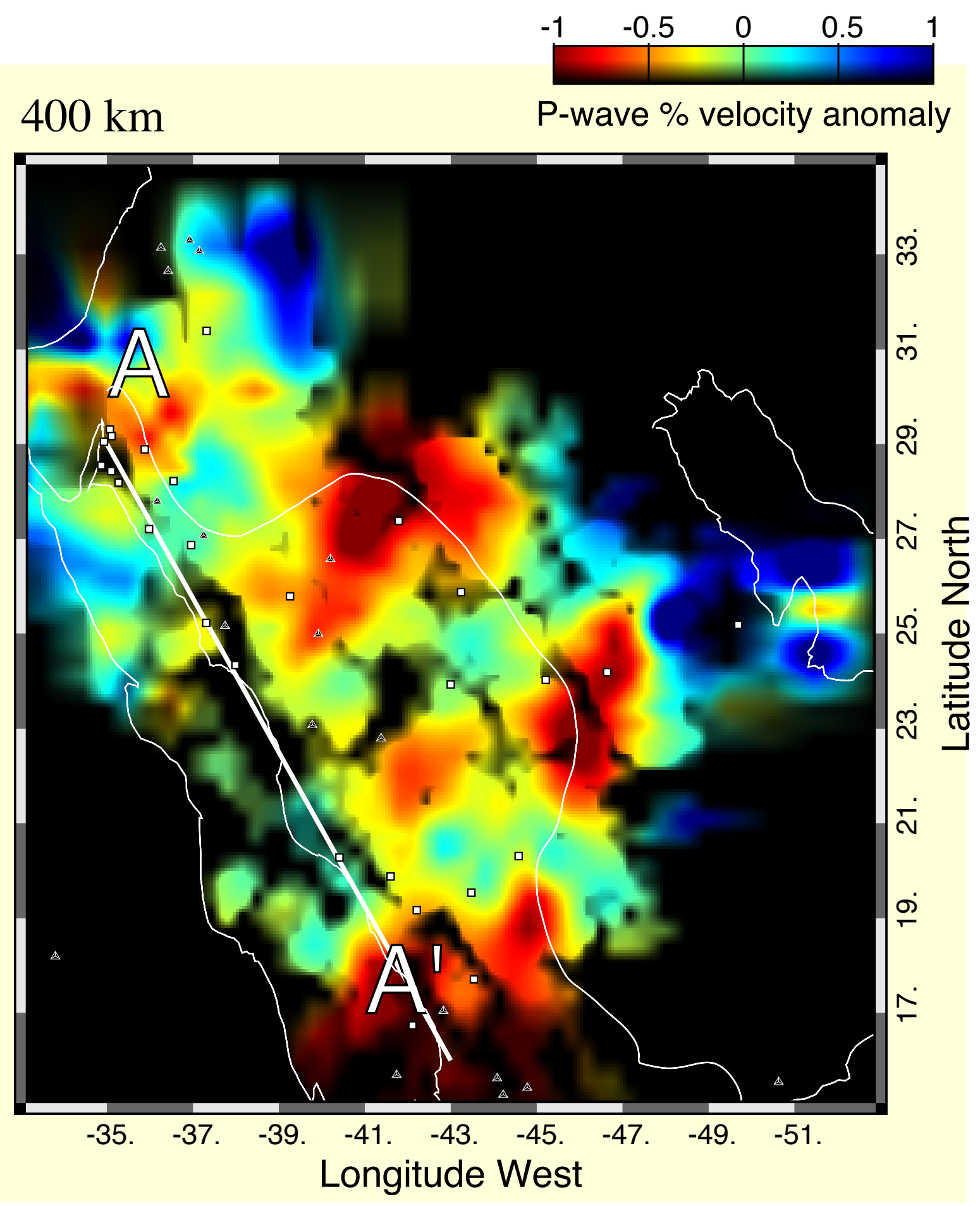

Figure 6. Same as Figure 3, but at $400 \mathrm{~km}$ depth. 


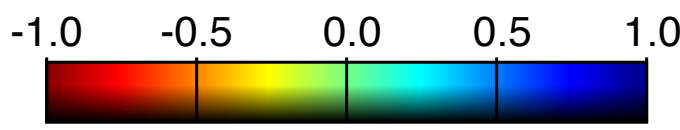

P-wave \% velocity anomaly

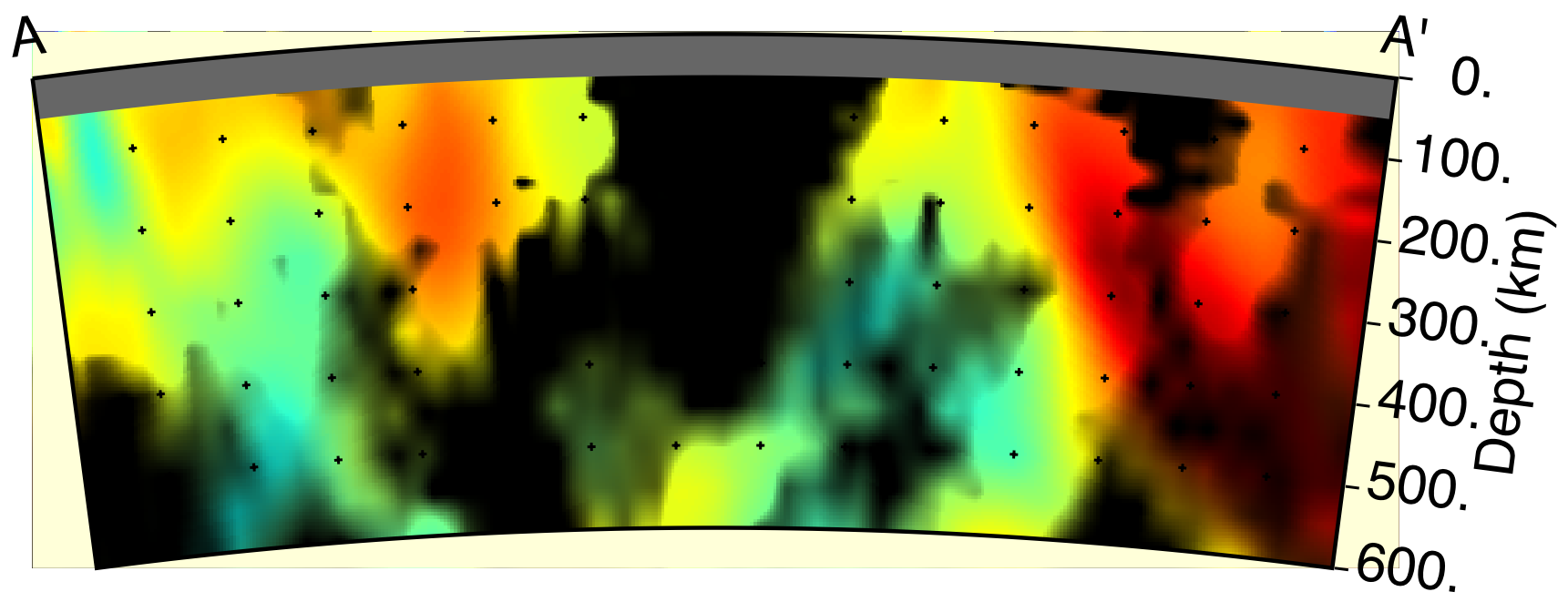

$A:(29.00 \mathrm{~N}, 35.00 \mathrm{E}) \quad \mathrm{A}^{\prime}:(16.00 \mathrm{~N}, 43.00 \mathrm{E})$

Figure 7. Cross-section through the upper mantle along the Red Sea coast (profile A-A' shown in Figure 1). 